\title{
IS WALKABILITY EQUALLY DISTRIBUTED AMONG DOWNTOWNERS? EVALUATING THE PEDESTRIAN STREETSCAPES OF EIGHT EUROPEAN CAPITALS USING A MICRO-SCALE AUDIT APPROACH
}

\author{
ALEXANDROS BARTZOKAS-TSIOMPRAS, ELEFTHERIA MARIA TAMPOURAKI \& YORGOS N. PHOTIS \\ Department of Geography \& Regional Planning, National Technical University of Athens, Greece
}

\begin{abstract}
In this paper, we evaluate different elements of the urban micro-scale environment in eight European capitals' downtown areas (i.e. Vienna, Copenhagen, Warsaw, Madrid, Brussels, Budapest, Athens and Sofia) to provide insight into inequalities in walkability benefits due to spatial distribution. To this end, we utilize MAPS-Mini, the brief version of Microscale Audit of Pedestrian Streetscapes to record and assess, at the street level, 15 walkability related items based on the Google Street View service. Our total sample consists of about 15.736 street segments/crossings, while for reliability analysis reasons, a second rater was employed to cross assess $10 \%$ of street segments per city. Results showed that Vienna and Athens had the highest $(50.4 \%)$ and lowest $(32.1 \%)$ overall walkability scores, respectively. Assessments were further combined with the population estimates of the European Urban Atlas 2012 dataset to perform equity analysis by estimating the distribution of average walkability scores among the population living downtown in the examined cities. In doing so, we used the Gini (G.) index and constructed Lorenz curve graphs. Our findings reveal a landscape of high inequality in downtown walkability distribution since all Gini coefficients were higher than 0.43 . However, the inequality was greatest in Brussels (G. =0.60) and lowest in Budapest (G. =0.43). Additionally, we used spatial statistics tests (i.e. global and local Moran's I) to identify global and local patterns of walkability and population. The results indicated a highly clustered pattern of walkability across all downtowns and designated several clusters of uneven walkability geographies. Our approach sheds light on the application of active mobility strategies in different European cities, highlighting at the same time the need for further research to provide a clearer assessment of the spatial distribution of inequalities in social benefits and impact when designing sustainable urban neighbourhoods.

Keywords: active mobility, downtown, city centre, walkability, urban planning, equality.
\end{abstract}

\section{BACKGROUND}

Walkability enhances wealth, improves health, contributes to climate change mitigation, promotes transportation fairness and increases social capital [2]. To this end, equality in access to walkable built environments is an important element and a critical feature of a sustainable and resilient city [1]. Despite that, vibrant and highly walkable neighbourhoods often experience significant gentrification pressures [3] due to the high level of reinvestment and soaring housing prices [1]. Consequently, various vulnerable groups (i.e. immigrants and the poor) are displaced and excluded from the benefits of walkable urbanism and it is then when decision and policy makers need to analyze and evaluate the uniform spatial distribution of well-engineered pedestrian environments throughout the society.

Based on a micro-scale audit of pedestrian streetscapes, this study investigates the potential inequities in walkability spatial distribution among people living in downtown neighbourhoods throughout Europe. This research topic, although new within environmental justice literature, remains largely unexplored in the European context, as strong attention has been made so far towards unfair accessibility to amenities, such as food markets, recreation, transit stations, healthcare and education facilities [4,5]. 
There is various, although mixed, evidence that socially disadvantaged groups have unequal spatial access to high-quality and walkable urban environments and that the effects of the built environment on walking and physical activity are weaker within vulnerable populations. Adkins et al. [6] demonstrated that socioeconomically advantaged groups in the USA, living in activity-supportive built environments, walked two-fold times more and were more physically active than disadvantaged populations. To the contrary, a Belgian study [7] indicated that a neighbourhood's socioeconomic conditions did not interact with the association between walkability and physical activity. Bereitschaft [4] used the WalkScore ${ }^{\circledR}$ index and found significant inequalities in access to walkable communities among vulnerable groups in three US cities. Similarly, Riggs [8] demonstrated that walkable housing in the San Francisco Bay area is not inclusive, and specific minorities, such as blacks, are more likely to reside in car-dependent communities. In Buffalo, NY, Knight et al. [3] found that high WalkScore ${ }^{\circledR}$ values are concentrated in the highly gentrifying central and western parts of the city, while the poor tend to live in disproportionately low walkability and isolated districts [3]. Moreover, a Chinese and a Spanish study $[9,10]$ reported that 15 min walkable neighbourhoods in Shenzhen are experiencing significant social inequalities, as spatial regression analysis showed positive correlations of adults and seniors with high walkability scores, but negative correlations of children and the nonresidential population. Respectively, in Madrid, the higher the socioeconomic neighbourhood status in the city, the lower the neighbourhood walkability index, while in gentrified and newly built areas this disadvantage was absent. Furthermore, a recent Scotland-based research [11] used a Geographic Information System (GIS)-based walkability index to demonstrate that higher area deprivation is not related to worse access to walkable areas.

Albeit all these walkability approaches are based on objectively measured macro-scale elements of urban form, such as population density, land-use mix, street network connectivity and transit/destination accessibility [12,[13], they do not consider the subtle differences of micro-scale urban environments. To this end, Bereitschaft [5] conducted a field survey in six streetscapes in Pittsburgh, PA, with equal macro-scale walkability (WalkScore ${ }^{\circledR}$ ) values and revealed distinctive differences in the quality and maintenance of the urban environment between more and less disadvantaged communities. Neckerman et al. [14], based on a New York City study, reported that microenvironment disparities are shown only in walkable neighbourhoods and that the advantages of the macro-scale built environment can be eliminated due to differences in neighbourhood conditions. These findings underline the significant limitations of macro-scale walkability research, which fails to reveal the inequalities between the various sociodemographic groups living in the city [15].

Although micro-scale built environment attributes, such as sidewalk quality, crossings, lighting, aesthetics, etc., have been less studied than the macro-scale environment details in walkability research, they can be easily modified and might have a direct impact on population's physical activity levels [16,17]. For example, Cain et al. [18] found that micro-scale environmental features were correlated significantly and positively to objectively measured physical activity across all ages. However, data on micro-scale characteristics of the built environment are often lacking and are measured subjectively [17].

So far, several micro-scale walkability audit tools have been developed, including the following: (1) the Irvine-Minnesota Inventory [15,19]; (2) the SPOTLIGHT-Virtual Audit Tool [20]; (3) the Walkability Audit Tool of Centers for Disease Control and Prevention (CDC) [21]; (4) the Pedestrian Environmental Data Scan (PEDS) [22]; and (5) the Microscale Audit of Pedestrian Streetscapes (MAPS) [18]. The MAPS audit tool is one of the most widely studied instruments in active transportation and physical activity research [18] and has been 
Table 1: Description of the pedestrian audit tool (Geremia and Cain [24]).

\begin{tabular}{|c|c|c|c|}
\hline Item & Theme & $\begin{array}{l}\text { Answer/ } \\
\text { points }\end{array}$ & Description \\
\hline \multirow[t]{2}{*}{ S1* } & \multirow[t]{2}{*}{ Land use Type } & 0 & Mainly residential or vacant space \\
\hline & & 1 & $\begin{array}{l}\text { Non-residential (e.g. commercial, education, rec- } \\
\text { reation etc.) }\end{array}$ \\
\hline \multirow[t]{3}{*}{$\mathbf{S} 2 *$} & \multirow{3}{*}{$\begin{array}{l}\text { Public parks or } \\
\text { plazas }\end{array}$} & 0 & No access to park/plaza \\
\hline & & 1 & One access point to park/plaza along the route rated \\
\hline & & 2 & $\begin{array}{l}\text { Two+ access points to park/plaza along the route } \\
\text { rated }\end{array}$ \\
\hline \multirow[t]{3}{*}{$\mathbf{S 3}$} & \multirow[t]{3}{*}{ Public transit } & 0 & No transit stop \\
\hline & & 1 & One transit stop \\
\hline & & 2 & Two or more transit stops \\
\hline \multirow[t]{2}{*}{ S4 } & \multirow[t]{2}{*}{ Public seating } & 0 & None \\
\hline & & 1 & Yes \\
\hline \multirow[t]{3}{*}{ S5 } & \multirow[t]{3}{*}{ Street lighting } & 0 & None \\
\hline & & 1 & Some \\
\hline & & 2 & Ample \\
\hline \multirow{4}{*}{ 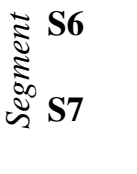 } & \multirow{4}{*}{$\begin{array}{l}\text { Building } \\
\text { maintenance } \\
\text { Graffiti }\end{array}$} & 0 & 0-99\% of buildings are well maintained \\
\hline & & 1 & $100 \%$ of buildings are well maintained \\
\hline & & 0 & Yes, the rated segment has at least one graffiti \\
\hline & & 1 & No, the rated segment is clean from graffiti \\
\hline \multirow[t]{3}{*}{ S8 } & \multirow[t]{3}{*}{ Cycling facilities } & 0 & No \\
\hline & & 1 & Painted cycle lane \\
\hline & & 2 & $\begin{array}{l}\text { Cycle lane separated from traffic with a physical } \\
\text { barrier }\end{array}$ \\
\hline \multirow[t]{2}{*}{ S9 } & \multirow[t]{2}{*}{ Sidewalk } & 0 & No \\
\hline & & 1 & Yes \\
\hline \multirow[t]{2}{*}{ S10 } & Sidewalk & 0 & Poor maintenance or no sidewalk present \\
\hline & maintenance & 1 & Well-kept sidewalk \\
\hline \multirow[t]{2}{*}{ S11* } & \multirow[t]{2}{*}{ Sidewalk buffer } & 0 & No or no sidewalk present \\
\hline & & 1 & Yes or it is a pedestrian/car-free street \\
\hline \multirow[t]{3}{*}{ S12 } & \multirow[t]{3}{*}{$\begin{array}{l}\text { Overhead coverage } \\
\text { (e.g. trees) }\end{array}$} & 0 & $\begin{array}{l}0-25 \% \text { of the walkway length is covered or no } \\
\text { sidewalk }\end{array}$ \\
\hline & & 1 & $26-75 \%$ of the walkway length is covered \\
\hline & & 2 & $76-100 \%$ of the walkway length is covered \\
\hline \multirow[t]{2}{*}{ C1_1 } & \multirow{2}{*}{$\begin{array}{l}\text { Pedestrian walk } \\
\text { signal }\end{array}$} & 0 & No \\
\hline & & 1 & Yes \\
\hline \multirow{3}{*}{ 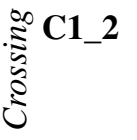 } & \multirow[t]{3}{*}{ Curb(s) ramp } & 0 & No \\
\hline & & 1 & Yes, at one curb only \\
\hline & & 2 & Yes, at both pre- and post-crossing curbs \\
\hline \multirow[t]{2}{*}{ C1_3 } & \multirow[t]{2}{*}{ Marked crosswalk } & 0 & No \\
\hline & & 1 & Yes \\
\hline
\end{tabular}

*Items are slightly differently defined in relation to the original MAPS-Mini guide. 
systematically tested for use either in online or field observations [23]. MAPS is a 120-item tool developed in the United States for physical activity research. It has three alternative versions according to different research or community practice purposes - the MAPS Abbreviated [16], a 54-item version; the MAPS mini [25], a 15-item version ideal for practitioners; and the MAPS Global [26], a 123-item version suitable for international use.

Drawing upon previous MAPS research, we develop a short, online and massive segmentbased walkability data collection method in eight different European downtown districts. Additional studies [27] from the United States have provided evidence that vibrant and walkable downtowns cause better mobility and health outcomes in the city. In this manner, we aim to quantify a micro-scale walkability indicator and, in turn, to reveal any potential walkability inequities among downtown residents. Although central urban cores are more walkable than suburban districts [1], we chose to focus on European downtowns as they often face significant socioeconomic segregation [28] and affordable housing issues [29], receive funds for costly regeneration and renewal projects [30] and play a critical role in daily city life. Therefore, this research seeks to answer the following questions:

1. Which downtown districts show the highest and lowest walkability performance?

2. Are walkable streetscapes of high quality distributed equally among downtowns?

3. Are walkability and population spatially clustered in downtown areas?

Findings from this study contribute mainly to the emerging European walkability literature as well as environmental justice research.

\section{METHODOLOGY}

\subsection{Microscale Audit of Pedestrian Streetscapes (MAPS) - mini version}

The brief (mini) version [25] of the 15-item Microscale Audit of Pedestrian Streetscapes (MAPS) tool [18] is simple, short and practical and facilitates our purposes for rapid, massive walkability data collection in many different city centres around Europe. Although MAPSMini was designed mainly for use by community groups and planning agencies, Sallis et al. [25] found that overall scores of the mini and the full MAPS versions are correlated positively at $r=0.85$, and the relationship of MAPS-Mini scores with active transport is linear and positive for all ages. All the relevant manuals and guides for any MAPS version are available online at http://sallis.ucsd.edu/measure_maps.html (Accessed 10/8/2019). Table 1 describes each item of the audit tool of this study, as well as the contributed points of each item and answers to the overall score per street segment. The 15 items of the survey were selected in terms of their correlation with physical activity, attributed modifiability and consistency with guidelines for activity-supportive neighbourhood environments [25]. The most significant difference between our approach and the original MAPS-Mini guide comes up in the first, second, and eleventh segment items. In the first item, we gave one point not only to commercial street segments but to every route where more than $50 \%$ of the walkway's length was not residential or vacant space and included essential facilities for daily errands and leisure, such as schools, banks, food markets, cafes, bars, healthcare, etc. Next, in the second item, we decided to consider not only public parks but also plazas because they are vital spaces in almost every European city for children to play, and for many adults and the 
elderly to meet. Last but not least, in the eleventh item, we attributed 1 point to segments that were pedestrian streets.

2.2 MAPS-Mini data collection, scoring and inter-rater reliability analysis

Due to limited resources and the high geographic diversity of our case studies, we conducted online audits. Phillips et al. [31] found that the results of virtual audits, conducted by observers living in different geographic areas, show a high level of agreement with in-person MAPS audits. Each 'virtual' trained observer used Google's Street View service to audit the streetscapes; all were unfamiliar with the assessment areas (except the case of Athens, Greece). In each downtown district, we performed segment-level data collection, and we covered separately each side of the street, block by block, as well as each crossing on both sides of the street. The data management of the whole process was done in ArcGIS software version 10.3 (ESRI, Redlands, CA, USA), while the answers to the survey were recorded in polylines representing each side of the block, as well as their crossings. The polyline data were created by splitting the polygons of the European Urban Atlas 2012 dataset [32] that provides land use information at block level for numerous functional urban areas in Europe. Concerning the calculation of scores $(0-100 \%)$ per each polyline record, we added up the total points of each rating, and then we divided the sum by 21 . Also, for reasons of inter-city comparisons, we calculated the overall city indicators for every individual item of the audit tool (i.e. weighted by polyline length). These indicators helped us to create the total score of walkability attractiveness for each downtown area, as we multiplied each with the relevant points per answer and in turn divided their sum by 21 . Finally, item-level reliabilities of a random sample of $10 \%$ of segments and their crossings per city were cross-assessed by a second rater. We used kappa statistics [33] for categorical variables and an intraclass correlation coefficient (ICC) [34] for overall walkability scores (continuous variables). According to Landis and Koch [33], the results of Cohen's kappa and ICC statistics indicate the following results about raters' agreement: 0.00-0.20: poor to slight; $0.21-0.40$ : fair; $0.41-0.60$ : moderate; 0.61-0.80: substantial; 0.81-1: almost perfect. This statistical analysis process was performed in SPSS version 23.0 (SPSS, Inc., Chicago, IL, USA).

\subsection{Equity analysis in walkability and data sources}

Equity pertains to the distribution of impacts, and this concept has been widely used in transportation planning decisions and transit research [35,36]. In this study, equity analysis in walkability refers to whether the distribution of walking-supportive neighbourhood designs is recognized as fair among the population residing in downtown districts. In practice, it is a horizontal equity concept where individuals should receive equal levels of walkability scores. To measure the level of equity in the distribution of walkability scores per each district, we used two classical measures. First, we employed the popular Gini coefficient $[35,[36]$ which is a global statistical measure of dispersion widely used in economic analysis, as well as Lorenz curve graphs [36] to illustrate and explain the level of inequality. The Gini coefficient (G.) ranges from 0 to 1 , where values near 1 indicate inequality and values close to 0 highlight equal distribution. The Lorenz curves (LCs) describe the cumulative distribution of benefits across the population. Thus, the diagonal line represents perfect equity, whereas the greater the area under that line, the higher the level of inequality in the distribution. To use these measures appropriately, we used two datasets. First, we utilized the population 
estimates of the European Urban Atlas 2012 (UA12) [32]. UA12 is a validated product created by an aerial interpolation GIS procedure; it is used by the European Commission's internal services to analyse population counts at high spatial detail [37]. However, in the case of Athens, Greece, we used the official population census 2011 [38], at block level as well. Second, for each polygon (i.e. city blocks) per downtown, we measured the average microscale walkability score. To do this, we converted all blocks to centroids, and from each of these points, we measured the mean walkability score of all overlapping segments at $250 \mathrm{~m}$ distance.

\subsection{Spatial clustering analysis with local Moran's I}

Spatial statistics measures can identify and map spatial clusters at global and local scales. First, we ran global statistical tests (i.e. global Moran's I) to determine in broad terms whether the patterns of walkability are clustered, random or dispersed. Second, since global tests do not report the locations or sizes of clusters, we drew upon local tests, such as univariate and bivariate local Moran's I spatial analysis [39]. Local Moran's index is a local indicator of spatial association (LISA) and has been widely used in geographical analyses to reveal hot and cold spots as well as to categorize them into spatial clusters or outliers [3,39]. Thus, to perform local spatial clustering analysis on micro-scale walkability scores, we used GeoDa 1.12.1.161. We calculated univariate local Moran's I statistics for each average walkability value per block (i.e. centroid) using a spatial weights matrix based on distance weights (250 m). Similarly, we applied bivariate local Moran's I statistics, which is a measure of spatial cross-correlation, to detect population clusters and walkability.

\subsection{Study areas}

The case studies were selected to include a geographically diverse group of European environments with different levels of economic development, heterogeneous urban mobility characteristics and various urban morphology features (i.e. population density). Also, the availability of recent (2011-2018) Street View imagery data was another primary criterion for the selection of cities (e.g. in German cities Google has an outdated Street View from 2008). Thus, the downtown areas of Madrid (ES), Athens (GR), Warsaw (PL), Budapest (HU), Vienna (AT), Brussels (BE), Copenhagen (DK) and Sofia (BG) were investigated. Table 2 depicts some essential characteristics of these cities, as well as some details about the downtown areas. All geospatial data regarding downtown boundaries were downloaded from OpenStreetMap.org, except in the case of Sofia, where the area denoted by Google Maps as the city centre was considered.

\section{RESULTS}

\subsection{MAPS-Mini survey results}

Overall, we rated and analysed 15.736 segments and 9.322 crossings (Table 2) from eight different European city centres. Table 3 shows the results for each item and the answers to the MAPS-Mini survey per examined city. In particular, Vienna showed the lowest share of mainly residential segments $(9.78 \%)$, while Athens demonstrated the highest percentage $(43.55 \%)$. Regarding the presence of segments with at least one access point to public parks 
Table 2: Description of selected cities and their downtown areas.

\begin{tabular}{|c|c|c|c|c|c|c|c|}
\hline \multirow[t]{3}{*}{ City } & \multirow{2}{*}{$\begin{array}{l}\text { Total } \\
\text { population } \\
\text { (2010) } \\
\text { (millions)* }\end{array}$} & \multirow{2}{*}{$\begin{array}{l}\text { Population } \\
\text { Weighted } \\
\text { Density } \\
(\text { inh./km²)* }\end{array}$} & \multirow{3}{*}{$\begin{array}{l}\text { Name of downtown } \\
\text { district(s) } \\
\text { (administrative) }\end{array}$} & \multirow[t]{2}{*}{$\begin{array}{l}\text { Study } \\
\text { area }\end{array}$} & \multicolumn{2}{|c|}{$\begin{array}{l}\text { Segments } \\
\text { assessed }\end{array}$} & \multirow[t]{2}{*}{$\begin{array}{l}\text { Crossings } \\
\text { assessed }\end{array}$} \\
\hline & & & & & MAPS-N & Mini & \\
\hline & \multicolumn{2}{|c|}{ Functional urban area } & & $\mathrm{km}^{2}$ & Number & $\mathrm{km}$ & Number \\
\hline Athens & 3.92 & 14,73 & 1st District & 7.2 & 4,505 & 307 & 2,678 \\
\hline Brussels & 2.45 & 5,89 & Pentagon & 4.2 & 1,782 & 162 & 1,025 \\
\hline Budapest & 2.88 & 5,13 & $\begin{array}{l}\text { District V \& parts } \\
\text { of Terézváros \& } \\
\text { Erzsébetváros } \\
\text { districts }\end{array}$ & 3.9 & 1,010 & 111 & 618 \\
\hline Copenhagen & 1.67 & 4,34 & Indre By & 10.4 & 1,659 & 191 & 879 \\
\hline Madrid & 6.25 & 18,8 & Centro & 5.2 & 2,512 & 222 & 1,418 \\
\hline Sofia & 1.43 & 5,69 & Център & 7 & 2,288 & 238 & 1,612 \\
\hline Vienna & 2.76 & 8,68 & Innere Stadt & 2.9 & 1,111 & 99 & 586 \\
\hline Warsaw & 3.08 & 3,97 & $\begin{array}{l}\text { Śródmieście } \\
\text { Północne and } \\
\text { Południowe }\end{array}$ & 5.9 & 869 & 125 & 506 \\
\hline
\end{tabular}

*Data Source: European Commission, DG JRC, Urban Data Platform, https://urban.jrc.ec.europa. eu/\#/en

or plazas, Copenhagen (23.42\%), Vienna (20.22\%) and Warsaw (20.33\%) scored very high, whereas Sofia $(7.7 \%)$ and Athens $(8.97 \%)$ had the lowest values. Warsaw (23.62\%) showed the highest number of segments with at least one public transit stop and Athens $(8.39 \%)$ presented the lowest percentage. Copenhagen's (29.36\%) and Budapest's (26.43\%) downtowns displayed the highest proportions of streets with available public seating facilities (e.g. benches), but Athens and Sofia demonstrated markedly lower values than the other cities with $11.47 \%$ and $11.51 \%$, respectively. Interestingly, Copenhagen $(3.62 \%)$ highlighted the highest share of segments with no lighting, but this was the result of including in our analysis some segments of high length that belonged to a large park that did not have any lights installed. However, in Sofia, 3.17\% of segments are unlit, while in Vienna the number of segments with ample lighting was the highest, at $29.78 \%$. Furthermore, in Vienna $(90.4 \%)$ and Copenhagen $(83.13 \%)$, the buildings were found to be well maintained in most of their segments, while in Sofia (78.75\%) and Athens (67.15\%), the buildings were generally rundown. Graffiti and vandalism were a serious and pressing issue for three downtown areas, namely Sofia (77.13\%), Madrid (70.02\%) and Athens (68.19\%), but in Vienna (9.09\%) and Copenhagen $(16.62 \%)$, this problem was far weaker. In the Athens city centre, we did not identify any segment with established cycling infrastructure, but Copenhagen showed the highest share of segments with protected bike lanes (27.68\%) and Brussels (11.28\%) demonstrated the highest percentage of segments with painted cycling lanes. Sofia's centre $(5.12 \%)$ was the area with the greatest number of segments without any sidewalk present, whereas Madrid $(0.55 \%)$ 
and Vienna $(0.73 \%)$ resulted in values under $1 \%$. Additionally, Sofia and Athens had the worst level of sidewalk maintenance at $58.77 \%$ and $31.92 \%$ of their segments, respectively. Next, in Sofia (74.68\%), we observed the highest number of sidewalk buffers, while to the contrary we identified the lowest share in Copenhagen (22.72\%). Sofia (55.62\%) and Athens $(53.38 \%)$ also had the highest share of segments with minimum overhead coverage or shading, while Brussels (16.85\%) presented the lowest value.

With respect to crossings, we identified the highest number of signalled crosswalks in Copenhagen (40\%) and the lowest in Sofia (13.64\%). Additionally, the highest number of crossings without ramps at any side of the curb as well as without any painted pedestrian crosswalk were found in downtown Athens at $59.83 \%$ and $82.31 \%$ of crossings, respectively.

Finally, in broad terms, Vienna's downtown demonstrated the best overall walkability score (50.45\%), while Athens's and Sofia's central cities showed the lowest values with $32.08 \%$ and $32.39 \%$, respectively. Copenhagen's and Warsaw's downtowns scored almost identical overall walkability scores with $48.93 \%$ and $48.48 \%$, respectively. Madrid's central district ranked in the fourth position with $46.46 \%$, while Brussels's and Budapest's urban cores resulted in the fifth and sixth ranks with $43.13 \%$ and $42.84 \%$, respectively.

\subsection{MAPS-Mini reliability analysis results}

Concerning crossing reliability, almost all items had a near perfect agreement, with kappa statistics values ranging from 0.659 to 1 . Specifically, the agreement between the observers in pedestrian signals item (C1_1) was perfect across all cities (Cohen's kappa > 0.971). Second, in segment reliability across all cases and items, we had moderate-to-perfect agreement. However, a fair agreement was indicated in Sofia's sample and at the cycling facilities item $($ Cohen's kappa $=0.395)$. Moderate agreement results $(0.48<$ Cohen's kappa $<0.60)$ were identified in four cities (Vienna, Warsaw, Budapest and Brussels) and three segment items (S1, S6 and S7). Finally, the ICC values for total scores were perfect in all areas (ICC >0.932). Results are described in Table 4.

\subsection{Equity analysis results}

Downtown Brussels showed the highest level of inequality $(\mathrm{G} .=0.606)$ in walkability distribution. Similarly, the central cores of Warsaw (G. =0.603) and Athens (G. =0.593) demonstrated significantly high levels of walkability inequality. To illustrate this kind of inequality, according to LCs (Fig. 1), about $25 \%$ of downtown residents in these three cities receive almost $72 \%$ of the total walkability scores. In Copenhagen's $(\mathrm{G} .=0.523)$ and Madrid's (G. $=0.496)$ central districts, the Gini indicators are lower, and about $25 \%$ of the population accumulates almost $63 \%$ of total walkability values. In Vienna's downtown $(\mathrm{G} .=0.463)$, $25 \%$ of downtown residents take roughly $59 \%$ of total walkability scores. On the other hand, Budapest's and Sofia's city centres present the lowest Gini coefficients, with 0.441 and 0.435 , respectively. The latter results, although they are the lowest Gini coefficients, mean that $25 \%$ of downtown residents receive about $56 \%$ of total walkability. To this end, Gini indicators and LCs from eight central districts around Europe underline relatively low horizontal equity in walkability distribution, since a significant part of high-quality walkable places is disproportionally available to a small number of residents. 
Table 3: Indicators per MAPS-Mini item and answer (weighted by polyline length) and overall walkability scores per downtown district.

\begin{tabular}{|c|c|c|c|c|c|c|c|c|c|c|}
\hline & Item & nswer & Athens & Sofia & Budapest & Brus & Madrid & Warsaw & $\mathrm{P}_{-}$ & $\overline{\text { Vienna }}$ \\
\hline \multirow{2}{*}{\multicolumn{2}{|c|}{ S1 }} & 0 & $43.55 \%$ & $32.49 \%$ & $19.34 \%$ & $33.73 \%$ & $20.06 \%$ & $23.66 \%$ & $42.98 \%$ & $9.78 \%$ \\
\hline & & 1 & $\%$ & $67.51 \%$ & $80.66 \%$ & $66.27 \%$ & 79.9 & 76 & $2 \%$ & $0.22 \%$ \\
\hline \multirow{3}{*}{\multicolumn{2}{|c|}{$\mathrm{S} 2$}} & 0 & $91.03 \%$ & $92.3 \%$ & $81.72 \%$ & $85.82 \%$ & $84.01 \%$ & $79.67 \%$ & $76.58 \%$ & $79.78 \%$ \\
\hline & & 1 & $2.62 \%$ & $0.79 \%$ & $2.2 \%$ & $1.73 \%$ & $2.32 \%$ & $1.93 \%$ & $3.67 \%$ & $1.33 \%$ \\
\hline & & 2 & $6.35 \%$ & $6.92 \%$ & $16.08 \%$ & $12.45 \%$ & $13.67 \%$ & $18.41 \%$ & $19.75 \%$ & $18.89 \%$ \\
\hline \multirow{3}{*}{\multicolumn{2}{|c|}{ S3 }} & 0 & $91.61 \%$ & $91.58 \%$ & $87.8 \%$ & $90.5 \%$ & $88.26 \%$ & $76.38 \%$ & $87.05 \%$ & $7.24 \%$ \\
\hline & & 1 & $38 \%$ & $7.17 \%$ & $8.42 \%$ & $8.11 \%$ & $9.93 \%$ & 16. & $11.28 \%$ & $10.08 \%$ \\
\hline & & 2 & $2 \%$ & 1.2 & $\%$ & $\%$ & $1.82 \%$ & $6.63 \%$ & $\%$ & $2.68 \%$ \\
\hline \multirow{2}{*}{\multicolumn{2}{|c|}{ S4 }} & 0 & $3 \%$ & $88.49 \%$ & 73.5 & $85.29 \%$ & 80 . & $77.03 \%$ & 70 & $77.79 \%$ \\
\hline & & 1 & $\%$ & 11. & 26 & 14 & $1 s$ & 22 & 25 & $22.21 \%$ \\
\hline \multirow{3}{*}{\multicolumn{2}{|c|}{ S5 }} & 0 & $\%$ & $\%$ & $\%$ & $\%$ & $0 \%$ & 0. & & $0.00 \%$ \\
\hline & & 1 & $\%$ & 86. & 76 . & & 78 & 76. & & $70.22 \%$ \\
\hline & & 2 & $\%$ & 10. & 22 & & $21.6 \%$ & $23.24 \%$ & & $29.78 \%$ \\
\hline \multirow{18}{*}{ 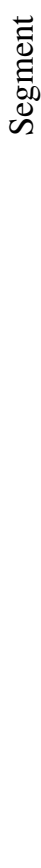 } & \multirow[t]{2}{*}{ S6 } & 0 & $\%$ & 78.7 & $\%$ & 38 & 28. & 29. & $7 \%$ & $9.6 \%$ \\
\hline & & 1 & $5 \%$ & $21.25 \%$ & 55. & 61. & 71. & 70 & $3 \%$ & $90.4 \%$ \\
\hline & \multirow[t]{2}{*}{ S7 } & 0 & $68.19 \%$ & $77.13 \%$ & $32 . c$ & $36.7 \%$ & 70 . & 46. & $16.62 \%$ & $9.09 \%$ \\
\hline & & 1 & $\%$ & 22. & 67 & 63 & 29 & 53 & $3 \%$ & $90.91 \%$ \\
\hline & \multirow[t]{3}{*}{ S8 } & 0 & $100.00 \%$ & $94.79 \%$ & $92.2 \%$ & $81.5 \%$ & $98.66 \%$ & $89.33 \%$ & $67.02 \%$ & $75.3 \%$ \\
\hline & & 1 & $0.00 \%$ & $1.69 \%$ & $6.03 \%$ & 11. & $0.95 \%$ & $3.54 \%$ & $1 \%$ & $9.89 \%$ \\
\hline & & 2 & $0.00 \%$ & $3.52 \%$ & $1.76 \%$ & $2 \%$ & $0.39 \%$ & $7.13 \%$ & 27 & $14.81 \%$ \\
\hline & \multirow[t]{2}{*}{ S9 } & 0 & $57 \%$ & $5.12 \%$ & $2.19 \%$ & $1.5 \%$ & $0.55 \%$ & $2.13 \%$ & $6 \%$ & $0.73 \%$ \\
\hline & & 1 & $43 \%$ & $94.88 \%$ & $97.81 \%$ & $98.5 \%$ & $99.45 \%$ & $97.87 \%$ & $97.84 \%$ & $99.27 \%$ \\
\hline & \multirow[t]{2}{*}{$\mathrm{S} 10$} & 0 & $2 \%$ & $58.77 \%$ & 10 . & $6.28 \%$ & $1.73 \%$ & $7.09 \%$ & $7 \%$ & $1.81 \%$ \\
\hline & & 1 & $\%$ & 41. & 89 & 93. & $98.27 \%$ & $1 \%$ & 94 & $98.19 \%$ \\
\hline & \multirow[t]{2}{*}{$\mathrm{S} 11$} & 0 & & 25 . & 72 & 66 & & $\%$ & & $.99 \%$ \\
\hline & & 1 & & 74.6 & & & & & & $26.01 \%$ \\
\hline & \multirow[t]{3}{*}{$\mathrm{S} 12$} & 0 & $\%$ & 44. & & 83 & 57 & & & $69.46 \%$ \\
\hline & & 1 & & 27 & & $\%$ & 22 & 24 & & $14.31 \%$ \\
\hline & & 2 & & 28. & & $\%$ & $3 \%$ & $3 \%$ & $\%$ & $16.23 \%$ \\
\hline & \multirow[t]{2}{*}{$\mathrm{C} 1 \_1$} & 0 & $2 \%$ & $86.36 \%$ & 83 & 79 & $81.5 \%$ & $65.93 \%$ & 60 & $75.11 \%$ \\
\hline & & 1 & $8 \%$ & $13.64 \%$ & $16.68 \%$ & $20.45 \%$ & $18.5 \%$ & $34.07 \%$ & $40.00 \%$ & $24.89 \%$ \\
\hline \multirow{5}{*}{ 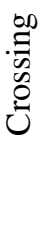 } & \multirow[t]{3}{*}{ C1_2 } & 0 & $59.83 \%$ & $47.48 \%$ & $5.3 \%$ & $10.61 \%$ & $3.04 \%$ & $3.75 \%$ & $2.7 \%$ & $1.01 \%$ \\
\hline & & 1 & $7.87 \%$ & $16.75 \%$ & $6.74 \%$ & $8.15 \%$ & $0.75 \%$ & $1.8 \%$ & $3.67 \%$ & $2.16 \%$ \\
\hline & & 2 & $32.3 \%$ & $35.77 \%$ & $87.96 \%$ & $81.24 \%$ & $96.21 \%$ & $94.45 \%$ & $93.63 \%$ & $96.83 \%$ \\
\hline & \multirow[t]{2}{*}{$\mathrm{C} 1 \_3$} & 0 & $82.31 \%$ & $79.91 \%$ & $68.6 \%$ & $23.62 \%$ & $33.61 \%$ & $19.31 \%$ & $42.26 \%$ & $49.19 \%$ \\
\hline & & 1 & $17.69 \%$ & $20.09 \%$ & $31.4 \%$ & $76.38 \%$ & $66.39 \%$ & $80.69 \%$ & $57.74 \%$ & $50.81 \%$ \\
\hline \multicolumn{3}{|c|}{ Overall score } & $32.08 \%$ & $32.39 \%$ & $42.84 \%$ & $43.13 \%$ & $46.16 \%$ & $48.48 \%$ & $48.93 \%$ & $50.45 \%$ \\
\hline
\end{tabular}


Table 4: Segments, crossings and score reliability analysis results.

\begin{tabular}{|c|c|c|c|c|c|c|c|c|}
\hline \multirow[b]{2}{*}{ Item } & Athens & Sofia & Copenhag & Madrid & Vienna & Warsaw & \multicolumn{2}{|c|}{ Budapest Brussels } \\
\hline & \multicolumn{8}{|c|}{ Cohen's kappa statistics } \\
\hline$\overline{C 1 \_1}$ & 1 & 0.971 & 0.972 & 1 & 1 & 1 & 1 & 1 \\
\hline C1_2 & 0.972 & 0.923 & 0.806 & $-{ }^{*}$ & 1 & 0.659 & 0.691 & 0.733 \\
\hline C1_3 & 0.99 & 0.98 & 0.983 & 0.988 & 0.946 & 0.823 & 0.924 & 0.948 \\
\hline S1 & 0.967 & 0.756 & 0.814 & 0.8 & 0.599 & 0.59 & 0.547 & 0.846 \\
\hline $\mathrm{S} 2$ & 1 & 0.936 & 0.92 & 0.953 & 0.678 & 0.646 & 0.643 & 0.942 \\
\hline S3 & 1 & 0.958 & 0.962 & 0.961 & 0.739 & 0.844 & 0.713 & 0.829 \\
\hline S4 & 0.938 & 0.939 & 0.917 & 0.937 & 0.683 & 0.888 & 0.789 & 0.896 \\
\hline S5 & 0.794 & 0.897 & 0.963 & 0.955 & 0.734 & 0.69 & 0.744 & 0.652 \\
\hline S6 & 0.973 & 0.921 & 0.802 & 0.883 & 0.598 & 0.714 & 0.571 & 0.485 \\
\hline S7 & 0.973 & 0.934 & 0.907 & 0.922 & 0.505 & 0.811 & 0.649 & 0.768 \\
\hline S8 & $-{ }^{*}$ & 0.395 & 0.974 & 1 & 0.812 & 1 & 0.572 & 0.859 \\
\hline S9 & 1 & 1 & $-^{*}$ & - $^{*}$ & 1 & 1 & - & 1 \\
\hline S10 & 0.896 & 0.942 & $-*$ & 1 & 0.791 & 0.788 & 0.712 & 0.71 \\
\hline S11 & 0.986 & 0.945 & 0.944 & 0.964 & 0.675 & 0.834 & 0.691 & 0.954 \\
\hline S12 & 0.829 & 0.953 & 0.813 & 0.902 & 0.608 & 0.592 & 0.704 & 0.691 \\
\hline ICC & 0.993 & 0.986 & 0.983 & 0.99 & 0.932 & 0.941 & 0.932 & 0.954 \\
\hline
\end{tabular}

*Variables are constant

\subsection{Spatial clustering results}

Figure 2 displays the maps of average walkability values per block in eight central European cities. The Global Moran's I results suggest that all walkability scores are highly clustered in all city centres. The lowest value of Moran's (Fig. 3) indicator can be found in Warsaw $(\mathrm{I}=0.548, \mathrm{p}<0.00)$, while the highest value is demonstrated in Budapest $(\mathrm{I}=0.906, \mathrm{p}<0.00)$. The univariate local Moran's I maps (Fig. 3) describe the locations of statistically significant $(\mathrm{p}<0.05)$ spatial clusters and outliers of walkability scores, and the results are classified into six groups: (1) high walkability clusters (scores are higher than expected by chance); (2) low walkability clusters (scores are lower than expected by chance); (3) high walkability outliers (scores are higher than expected by chance, but the scores of their neighbours are lower than expected by chance); (4) low walkability outliers (scores are lower than expected by chance, but scores of their neighbours are higher than expected by chance); (5) not significant (scores are equal to what is expected by chance alone); (6) Neighbourless (there is no neighbour, given the defined distance $-250 \mathrm{~m}$ - during the spatial weights matrix calculation).

In five cities, Madrid, Brussels, Budapest, Sofia and Athens, we have identified a large hotspot area of high walkability scores, surrounded by several smaller enclaves of low walkability. These high-quality pedestrian-oriented environments are located at the 'heart' of each downtown, and they have recently seen major urban transformations. For example, Brussels's and Madrid's [30] urban 'hearts' are experiencing large renewal projects, aiming to create extensive car-free and high-quality engineered central neighbourhoods. On the other hand, 
Brussels (Gini=.606)

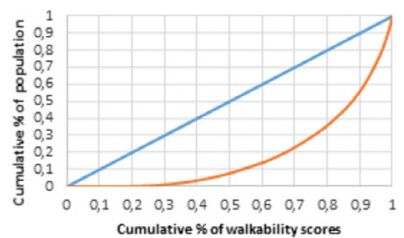

Copenhagen (Gini=.523)

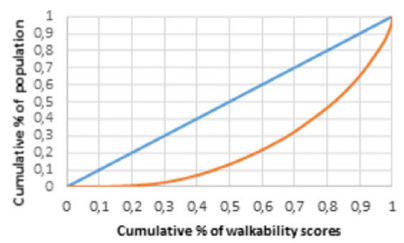

Sofia (Gini=.441)

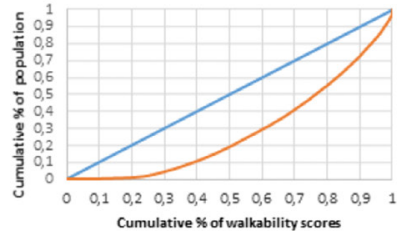

Warsaw (Gini=.603)

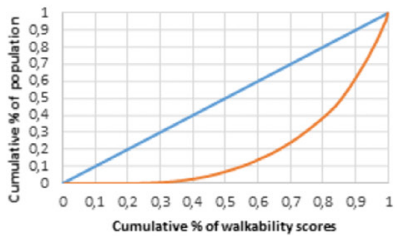

Madrid (Gini=.496)

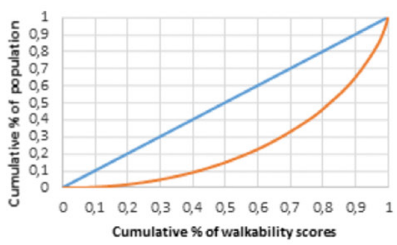

Budapest (Gini=.435)

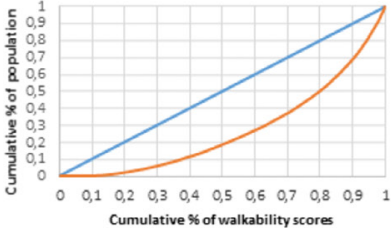

Athens (Gini=.593)

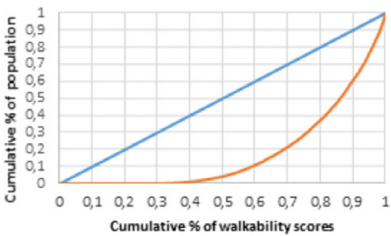

Vienna (Gini $=.463$ )

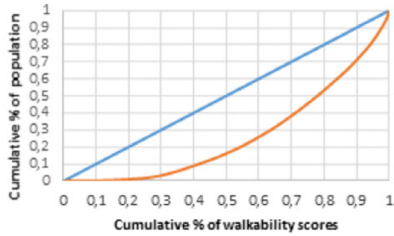

Figure 1: Gini coefficient values and Lorenz curve graphs per downtown district.
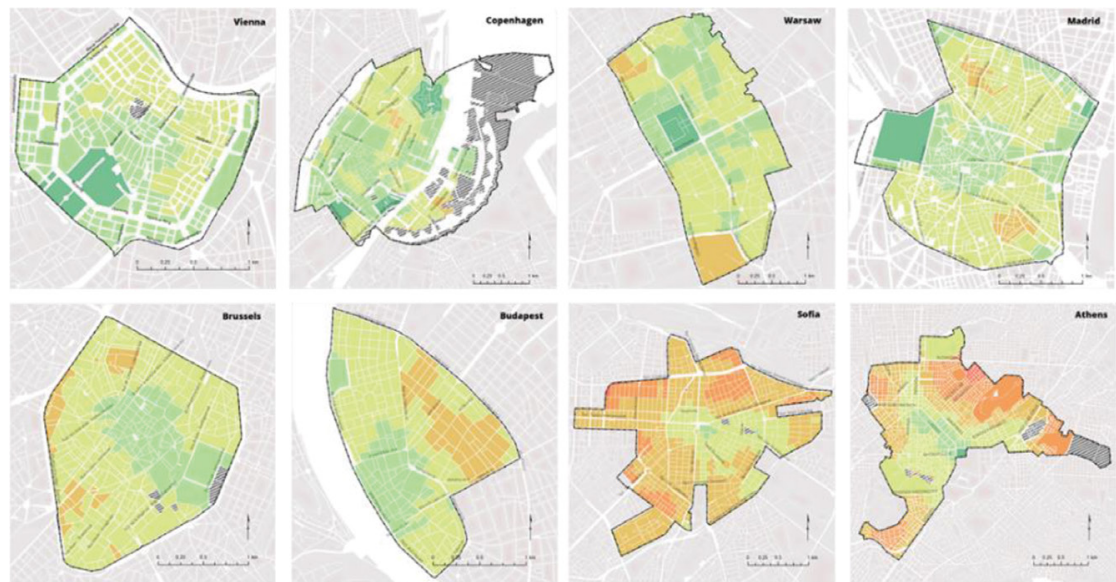

Average Score/ Block

0-10

$=10-20$

- $30-40$

40-50

$50-60$

$50-70$
$70-80$

$\begin{array}{r}70-80 \\ \quad \mathbf{r}-90 \\ \hline\end{array}$
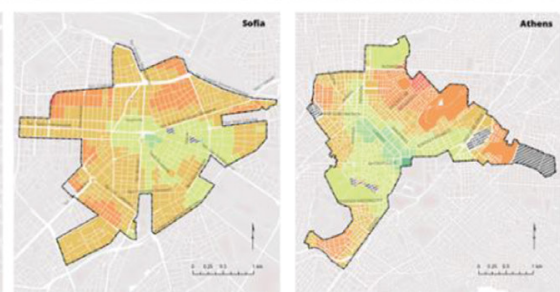

- 90-100

\section{E.:.'Boundary}

< No Data

Other Areas

Figure 2: Spatial distribution of average micro-scale walkability scores per block. 

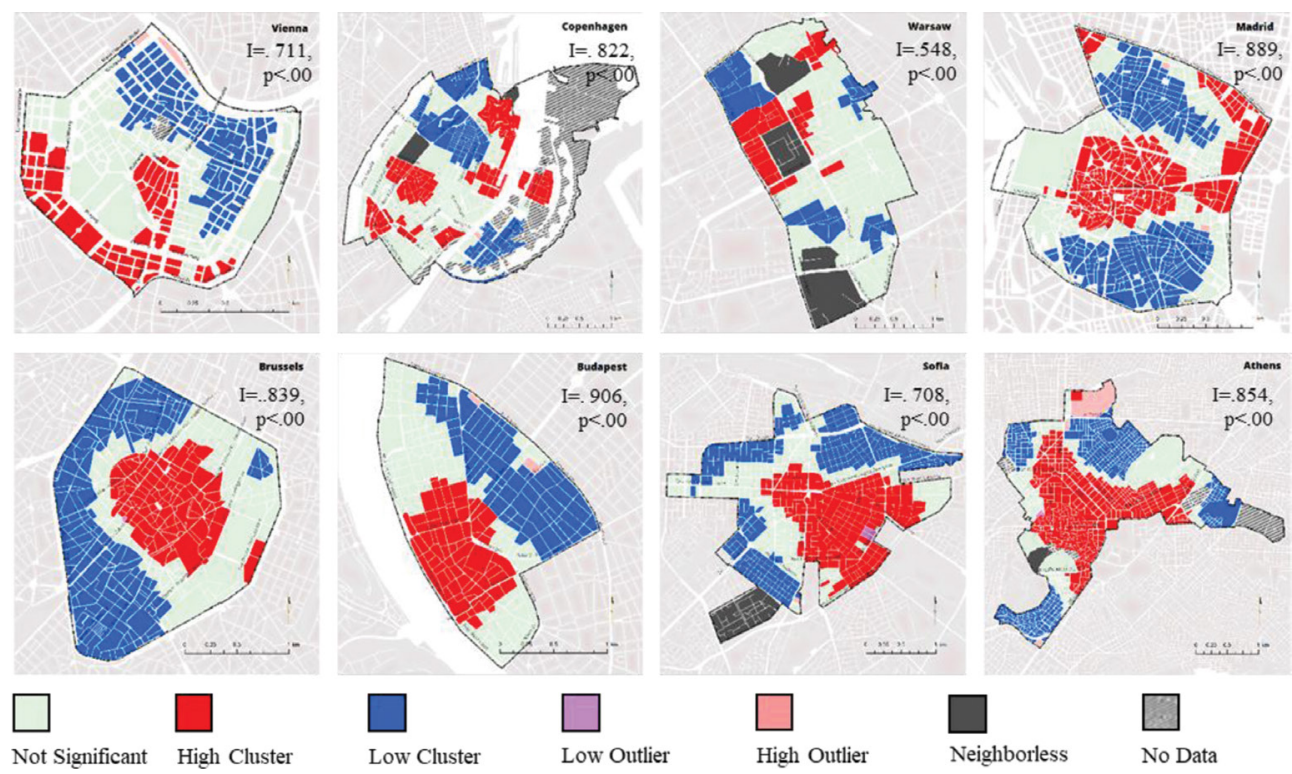

Figure 3: Spatial clusters/outliers of walkability per downtown (I = global Moran's index).

the cold spots of walkability are concentrated in districts that have chronically been excluded from urban policy shifts. For instance, in Athens neighbourhoods such as Exarcheia and Plateia Vathis, wherein various socially vulnerable groups reside (e.g. immigrants and the homeless), the streetscape walkability is lower than in more affluent areas (i.e. Kolonaki). In Vienna, the northern parts of the downtown seemingly show lower quality pedestrian environments in relation to southern and central parts that demonstrate extremely high-quality walkability features. In Copenhagen and Warsaw, we found several and dispersed clusters of low and high walkability enclaves, as well as many blocks that were classified as not significant. However, in Warsaw, due to huge block sizes, we had four neighbourless polygons. The number of blocks identified as low or high spatial outliers of walkability was negligible for all downtowns.

The bivariate local Moran's I maps (Fig. 4) display the spatial association of local populations living downtown and the micro-scale average walkability scores. In bivariate maps, the results are grouped into the following categories: (1) high population and high walkability; where a considerable proportion of downtown residents live in high-quality environments; (2) low population and high walkability, where in most cases these blocks pertain to parts of the city that encompass mainly large green, business or public areas of very low population densities; (3) high population and low walkability, wherein dwellers are more disadvantaged and live in lower quality places; (4) low population and low walkability, which often relate to military establishments or brownfield areas, with low levels of residences and non-activitysupportive built environments; (5) not significant or neighbourless, the explanation for these two groups is quite similar to those of univariate walkability cluster types.

In Athens (29.44\%), Madrid (20.71\%) and Budapest (20.48\%), we identified the highest shares of areas with high walkability scores and low population (Table 5). These clusters are often located at the urban 'heart' (Fig. 4) and characterized as central business, tourism and/or government districts, wherein housing opportunities and practical affordability [29] 
Table 5: Percentage of blocks area per bivariate (population and walkability) cluster type.

\begin{tabular}{lcccccc}
\hline City & \multicolumn{6}{c}{ Bivariate cluster types (Local Moran's I) } \\
\cline { 2 - 7 } & $\begin{array}{l}\text { Not sig- } \\
\text { nificant }\end{array}$ & $\begin{array}{l}\text { High } \\
\text { population } \\
\text { - high } \\
\text { walkability }\end{array}$ & $\begin{array}{l}\text { Low } \\
\text { population }\end{array}$ & $\begin{array}{l}\text { Low } \\
\text { population } \\
\text { walkability }\end{array}$ & $\begin{array}{l}\text { - high } \\
\text { - low } \\
\text { walkability } \\
\text { walkability }\end{array}$ & $\begin{array}{l}\text { Neigh- } \\
\text { bourless }\end{array}$ \\
\hline Vienna & $47.03 \%$ & $8.34 \%$ & $10.37 \%$ & $15.94 \%$ & $18.32 \%$ & $0 \%$ \\
Copenhagen & $44.49 \%$ & $9.32 \%$ & $9.98 \%$ & $16.49 \%$ & $15.95 \%$ & $3.78 \%$ \\
Warsaw & $50.35 \%$ & $6.90 \%$ & $3.70 \%$ & $6.13 \%$ & $13.15 \%$ & $19.77 \%$ \\
Madrid & $26.64 \%$ & $6.94 \%$ & $12.21 \%$ & $20.71 \%$ & $24.15 \%$ & $9.35 \%$ \\
Brussels & $34.95 \%$ & $5.79 \%$ & $13.12 \%$ & $18.27 \%$ & $27.87 \%$ & $0 \%$ \\
Budapest & $37.47 \%$ & $6.69 \%$ & $7.63 \%$ & $20.48 \%$ & $27.73 \%$ & $0 \%$ \\
Sofia & $29.44 \%$ & $16.55 \%$ & $16.62 \%$ & $16.07 \%$ & $14.54 \%$ & $6.77 \%$ \\
Athens & $28.46 \%$ & $8.22 \%$ & $17.19 \%$ & $29.44 \%$ & $15.05 \%$ & $1.65 \%$ \\
\hline
\end{tabular}
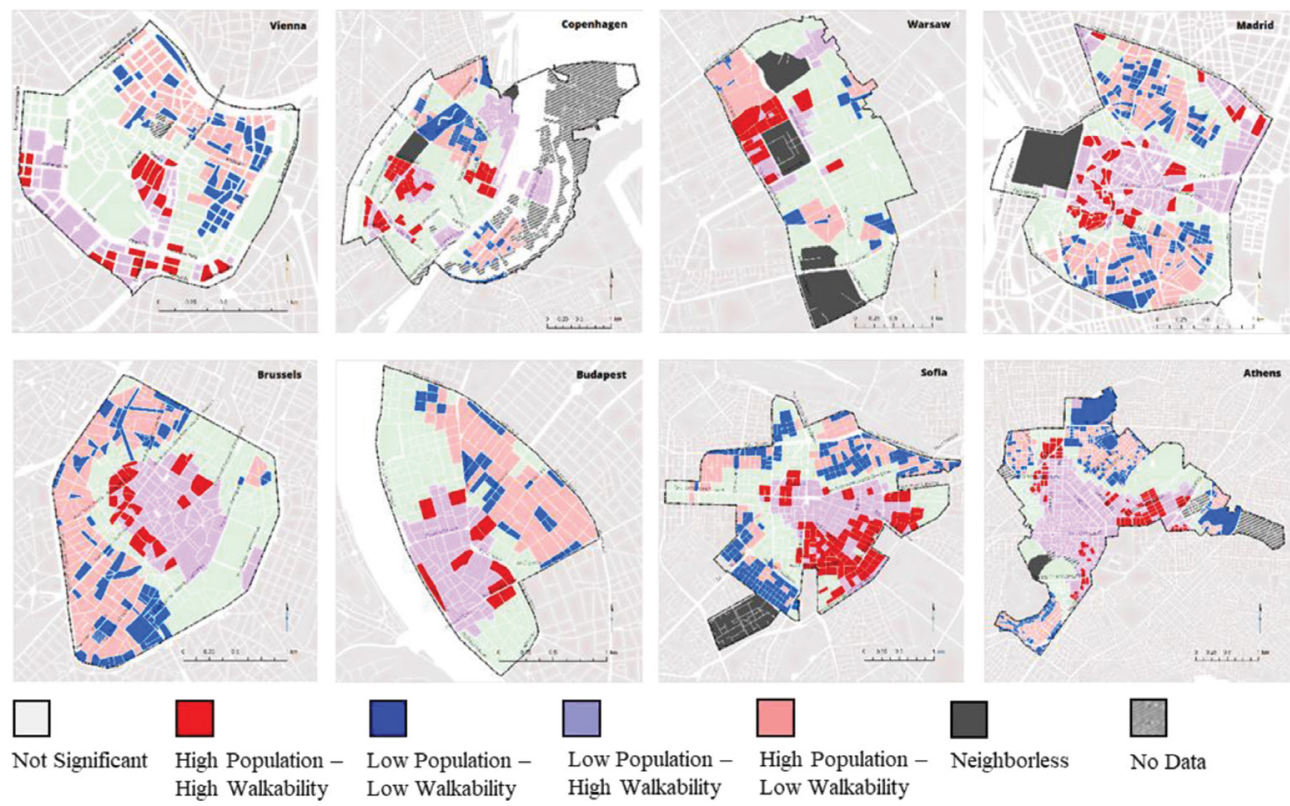

Figure 4: Bivariate local Moran's I cluster results (population and walkability).

mechanisms are slow to develop due to increasing rental prices driven by the walkability advantage [1]. This finding is consistent with other studies [3,8] that identified similarly alarming characteristics of high walkability in central places that exclude residents. Additionally, in Brussels (27.87\%), Budapest (27.73\%) and Madrid (24.15\%), we highlighted more than $20 \%$ of areas with disadvantaged populations that reside in low-quality urban environments (Table 4). These locations are mainly residential and they are seemingly concentrated 
at the periphery of each downtown (i.e. the lower side of Christianshavn in Copenhagen, the Embajadores neighbourhood in Madrid, the Senne district in Brussels and the southwest Erzsébetváros area in Budapest). Thus, expansion of this analysis is required to understand if and to what extent this spatial disadvantage continuously affect people living at greater distances from the urban core. Interestingly, in Sofia (16.55\%), we detect a high share of area with a high population and high walkability, which partially explains our previous result about Sofia's lower level in walkability inequality (Fig. 1). In all other cases, the high-high clusters were attributed to less than $9.32 \%$ of the total area. However, Athens (17.19\%) and Sofia $(16.62 \%)$ presented significant shares of blocks with low population and low walkability, which means that they could target these areas as potential locations for future urban renewal and reinvestments programs.

\section{CONCLUSION}

Everyone should have the right to live in high-quality and well-engineered sustainable urban environments with decent and accessible public transit options and multiple destinations nearby to walk safely and comfortably. To this end, several environmental and public health organizations have been calling for walkable urbanism to decrease the unsustainable impacts of car-based lifestyles and prioritize active mobility as a means to deal with the physical inactivity epidemic [2]. However, the spatial patterns of walkable neighbourhoods vary at different scales by socioeconomic context, and social inequalities are created [9]. In this study, we underlined the differences in measuring walkability between macro-scale and micro-scale approaches [5], and we applied a massive data collection process in eight European downtowns to calculate a micro-scale walkability index. We audited online 15.736 street segments and 9.322 pedestrian crossings, using the MAPS-Mini tool [25] and created average walkability scores per downtown block. The aim of this measurement was first to compare the differences in pedestrian microenvironments and second to find which downtown areas score the highest or lowest overall walkability attractiveness. Although the improvement of the examined microenvironment characteristics is a low-cost solution that requires short-term schemes [17] (i.e. graffiti removal), we identified striking differences between European central cities walkability attributes (Table 3 ). We concluded that Vienna and Copenhagen are the top walkable downtowns, while Athens's and Sofia's urban cores are the worst cases in terms of micro-scale walkability.

Next, we applied equity analysis in downtown micro-scale walkability values to answer the second question regarding the horizontal inequities of walkability distribution within European downtown areas. This question is crucial for urban sustainability; studies from the United States have demonstrated that downtown vibrancy is related to more population-level health and safety outcomes [27]. Therefore, we found that in all investigated European urban cores, walkability is highly unequally distributed among downtown residents, where in some cases (Brussels, Warsaw and Athens), one-fourth of the population receives about $75 \%$ of the total walkability scores. All Gini indicators were higher than 0.43 , highlighting a landscape of great inequality that needs further socioeconomic and demographic investigation. This evidence is alarming for the urban planning scholarship since it proves that existing practice is not able to support inclusiveness in the intra-neighbourhood design, even at the most walkable part of a city, the downtown. However, similar Gini indicators in walkability are missing from other studies, and our results could not be compared to other regions.

Concerning the third question, we found that in all city centres walkability is highly clustered but at different magnitudes. We detected spatial clusters and outliers of walkability, as well as spatial clusters in terms of population and walkability altogether (Figs 3 and 4). 
Cluster analysis helped us to demonstrate the highly unequal geographic distribution of walkability across the population in all downtowns, as we detected that the majority groups are concentrated mostly in deprived enclaves of low-quality environments at the periphery of the downtown. Nonetheless, high walkability clusters are often concentrated at the urban 'heart' of each downtown, but at the same time these high-quality environments can hardly be inhabited by many people. Notably, these 'uninhabited' and highly walkable clusters in seven of eight downtowns exceed $15 \%$ of the total area. Although we do not have available data about the housing markets and the sociodemographics for each region, we speculate that this result is influenced directly by increased rental prices and housing affordability/availability issues [1] that in turn exacerbate and preserve inner-city social inequalities. Similar findings have been made by Knight et al. [3], where walkable and central blocks in Buffalo, NY, were highly clustered and gentrified. Furthermore, even in more developed cities with a high-quality of living, such as Vienna or Copenhagen, further efforts for renewal are needed, as we detected almost in all downtowns a significantly high number of isolated clusters where the population is high but the walkability poor. Nevertheless, since many renewal schemes are proposed or currently underway across European cities, their impacts on social cohesion should be fully acknowledged in the decision-making process.

Overall, this article has demonstrated how the concept of short US-based pedestrian audit tools can be operationalized to quantify and map micro-scale walkability attractiveness and equity in Europe. Our findings suggest that actions to improve walkability and the quality of downtown neighbourhoods should be entirely connected to socioeconomic and demographic justice targets. Evidence of highly unequal walkable downtowns across Europe reflects the broader socioeconomic inequities [28] of cities and critically hinders every path towards sustainable urban development.

However, certain limitations should be acknowledged. First, the boundaries of each downtown district are not commonly defined, and thus comparability between different areas is limited. Second, the online data collection process is based on Street View images captured at different time periods. Thus, observers provide walkability ratings that in some cases are outdated, but in other cases are quite recent. Third, the average walkability scores of blocks located at the boundary edges are biased, since ratings for segments and crossings outside the boundary are missing. Furthermore, the streetscape assessment process is human intensive, and it is difficult to implement at the metropolitan level. Last but not least, lack of fine-scale pan-European urban demographic data (i.e. on the elderly, children, youth, gender, etc.) and the socioeconomic conditions limits this research as well. Future researchers could expand and improve upon our approach in more downtown areas to cross assess and monitor the changing pedestrian microenvironment dynamics as well as to cross-correlate micro-scale walkability with travel behaviours and other sociospatial phenomena.

\section{ACKNOWLEDGEMENTS}

This research was co-financed by Greece and the European Union (European Social Fund) in the context of the project 'Strengthening Human Resources Research Potential via Doctorate Research' (MIS-5000432) implemented by the State Scholarships Foundation.

\section{REFERENCES}

[1] Gilderbloom, J.I., Riggs, W.W. \& Meares, W.L., Does walkability matter? An examination of walkability's impact on housing values, foreclosures and crime. Cities, 42(PA), pp. 13-24, 2015. 
[2] Speck, J., Walkable City Rules: 101 Steps to Making Better Places, Island Press: Washington, DC, 2018.

[3] Knight, J., Weaver, R. \& Jones, P., Walkable and resurgent for whom? The uneven geographies of walkability in Buffalo, NY. Applied Geography, 92, pp. 1-11, 2018.

[4] Bereitschaft, B., Equity in neighbourhood walkability? A comparative analysis of three large U.S. cities. Local Environment, 22(7), pp. 859-879, 2017.

[5] Bereitschaft, B., Equity in microscale urban design and walkability: A photographic survey of six Pittsburgh streetscapes. Sustainability (Switzerland), 9(7), p. art. no. 1233, 2017.

[6] Adkins, A., Makarewicz, C., Scanze, M., Ingram, M. \& Luhr, G., Contextualizing walkability: Do relationships between built environments and walking vary by socioeconomic context? Journal of the American Planning Association, 83(3), pp. 296-314, 2017.

[7] Van Dyck, D., et al., Neighborhood SES and walkability are related to physical activity behavior in Belgian adults. Preventive Medicine, 50(SUPPL.), pp. S74-S79, 2010.

[8] Riggs, W., Inclusively walkable: Exploring the equity of walkable housing in the San Francisco bay area. Local Environment, 21(5), pp. 527-554, 2014.

[9] Weng, M., et al., The 15-minute walkable neighborhoods: Measurement, social inequalities and implications for building healthy communities in urban China. Journal of Transport and Health, 13, pp. 259-273, 2019.

[10] Gullón, P., et al., Intersection of neighborhood dynamics and socioeconomic status in small-area walkability: The Heart Healthy Hoods project. International Journal of Health Geographics, 16(1), p. art.no.21, 2017.

[11] Kenyon, A. \& Pearce, J., The socio-spatial distribution of walkable environments in urban scotland: A case study from Glasgow and Edinburgh. SSM - Population Health, 9, p. art.no.100461, 2019.

[12] Frank, L.D., et al., The development of a walkability index: Application to the neighborhood quality of life study. British Journal of Sports Medicine, 44(13), pp. 924 933, 2010.

[13] Bartzokas-Tsiompras, A. \& Photis, Y.N., What matters when it comes to "walk and the city"? Defining a weighted GIS-based walkability index. Transportation Research Procedia, 24, pp. 523-530, 2017.

[14] Neckerman, K.M., et al., Disparities in urban neighborhood conditions: Evidence from GIS measures and field observation in New York city. Journal of Public Health Policy, 30(SUPPL.1), pp. S264-S285, 2009.

[15] Koschinsky, J., Talen, E., Alfonzo, M. \& Lee, S., How walkable is Walker's paradise? Environment and Planning B: Urban Analytics and City Science, 44(2), pp. 343-363, 2017.

[16] Cain, K.L., et al., Developing and validating an abbreviated version of the Microscale Audit for Pedestrian Streetscapes (MAPS-Abbreviated). Journal of Transport and Health, 5, pp. 84-96, 2017.

[17] Sallis, J.F., et al., Income disparities in perceived neighborhood built and social environment attributes. Health and Place, 17(6), pp. 1274-1283, 2011.

[18] Cain, K.L., et al., Contribution of streetscape audits to explanation of physical activity in four age groups based on the Microscale Audit of Pedestrian Streetscapes (MAPS). Social Science and Medicine, 116, pp. 82-92, 2014. 
[19] Day, K., Boarnet, M., Alfonzo, M. \& Forsyth, A., The Irvine-Minnesota inventory to measure built environments: Development. American Journal of Preventive Medicine, 30(2), pp. 144-152, 2006.

[20] Bethlehem, J.R., et al., The SPOTLIGHT virtual audit tool: A valid and reliable tool to assess obesogenic characteristics of the built environment. International Journal of Health Geographics, 13(1), p. art. no. 52, 2014.

[21] Dannenberg, A.L., Cramer, T.W. \& Gibson, C.J., Assessing the walkability of the workplace: A new audit tool. American Journal of Health Promotion, 20(1), pp. 39-44, 2005.

[22] Clifton, K.J., Livi Smith, A.D. \& Rodriguez, D., The development and testing of an audit for the pedestrian environment. Landscape and Urban Planning, 20(1-2), pp. 95110, 2007.

[23] Zhu, W., et al., Reliability between online raters with varying familiarities of a region: Microscale Audit of Pedestrian Streetscapes (MAPS). Landscape and Urban Planning, 167, pp. 240-248, 2017.

[24] Geremia, C., \& Cain, K., MAPS-Mini, 2015. [Online]. Available: http://sallis.ucsd. edu/Documents/Measures_documents/MAPS-Mini\%20Field\%20Procedures $\% 20 \% 20$ Picture\%20Guide_090815.pdf. [Accessed 108 2019].

[25] Sallis, J.F., et al., Is your neighborhood designed to support physical activity? A brief streetscape audit tool. Preventing Chronic Disease, 12(9), p. art. no. 150098, 2015.

[26] Cain, K.L., et al., Development and reliability of a streetscape observation instrument for international use: MAPS-global. International Journal of Behavioral Nutrition and Physical Activity, 15(1), p. art. no. 19, 2018.

[27] Braun, L.M. \& Malizia, E., Downtown vibrancy influences public health and safety outcomes in urban counties. Journal of Transport and Health, 2(4), pp. 540-548, 2015.

[28] Tammaru, T., Marcińczak, S., Van Ham, M. \& Musterd, S., Socio-economic segregation in European capital cities: East meets West, Taylor and Francis Inc., 2015.

[29] Inchauste, G., Karver, J., Kim, Y. S. \& Jelil, M. A., Living and leaving. housing, mobility, and welfare in the European Union, World Bank Report. [Online]. Available: http:// pubdocs.worldbank.org/en/507021541611553122/Living-Leaving-web.pdf. [Accessed 20198 5].

[30] Chaplain, C., The European cities leading the way in car-free living in a bid to tackle toxic air pollution, 2017. [Online]. Available: https://www.standard.co.uk/news/ transport/the-european-cities-leading-the-way-in-carfree-living-in-a-bid-to-tackletoxic-air-pollution-a3658216.html. [Accessed 178 2019].

[31] Phillips, C.B., et al., Online versus in-person comparison of Microscale Audit of Pedestrian Streetscapes (MAPS) assessments: Reliability of alternate methods. International Journal of Health Geographics, 16(27), 2017.

[32] European Environment Agency, Urban Atlas 2012. [Online]. Available: https:// www.eea.europa.eu/data-and-maps/data/copernicus-land-monitoring-service-urbanatlas\#tab-gis-data. [Accessed 108 2019].

[33] Landis, J.R. \& Koch, G.G., The measurement of observer agreement for categorical data. Biometrics, 33(1), pp. 159-174, 1977.

[34] Shrout, P.E., Measurement reliability and agreement in psychiatry. Statistical Methods in Medical Research, 7(3), pp. 301-317, 1998. 
[35] Bartzokas-Tsiompras, A. \& Photis, Y. N., Measuring rapid transit accessibility and equity in migrant communities across 17 European cities. International Journal of Transport Development and Integration, 3(3), pp. 245-258, 2019.

[36] Delbosc, A. \& Currie, G., Using Lorenz curves to assess public transport equity. Journal of Transport Geography, 19(6), pp. 1252-1259, 2011.

[37] Batista E Silva, F., Poelman, H., Martens, V. \& Lavalle, C., Population estimation for the Urban Atlas Polygons, European Commision, JRC Technical Reports, 2013. [Online]. Available: http://dx.doi.org/10.2788/54791. [Accessed 108 2019].

[38] ELSTAT, Population Census 2011, 2011. [Online]. Available: http://www.statistics.gr/ en/home/.

[39] Anselin, L., Local Indicators of Spatial Association-LISA. Geographical Analysis, 27(2), pp. 93-115, 1995 